\title{
Young FADOI and gender medicine: sex gender differences in cardiovascular disease
}

\author{
Tiziana Ciarambino, ${ }^{1}$ Miriam Gino, ${ }^{2}$ Paola Gnerre, ${ }^{3}$ Elena Barbagelata, ${ }^{4}$ Nunzia Barone, ${ }^{5}$ Francesca Saladini, ${ }^{6}$ \\ Federica Lorenzi, ${ }^{7}$ Marta Zanon, ${ }^{8}$ Maria Cristina Pasquini, ${ }^{9}$ Cecilia Politi ${ }^{1}$
}

${ }^{1}$ Department of Internal Medicine, F. Veneziale Hospital, Isernia; ${ }^{2}$ Department of Internal Medicine, Rivoli Hospital, Rivoli (TO); ${ }^{3}$ Department of Internal Medicine, San Paolo Hospital, Savona; ${ }^{4}$ Department of Internal Medicine, Sestri Levante Hospital,

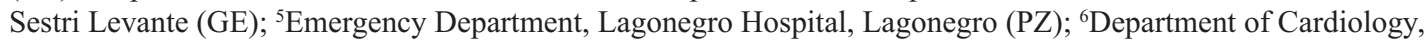
Camposampiero Hospital, Camposampiero (PD); ${ }^{7}$ Department of Internal Medicine, Sandro Pertini Hospital, Roma; ${ }^{8}$ Department of Internal Medicine, dall'Angelo Hospital, Venezia; ${ }^{9}$ Department of Oncology, Maggiore Hospital, Crema (CR), Italy

\begin{abstract}
We have evaluated gender-related differences in cardiovascular disease. In particular, in coronary heart disease, atrial fibrillation, arterial hypertension, venous thromboembolism and diabetes mellitus.
\end{abstract}

\section{Coronary disease: gender-related differences}

\section{Introduction}

Bernardine Healy, in an editorial of 1991 on the NEJ The Yentl Syndrome, ${ }^{1,2}$ showed how cardiovascular disease in women is understudied, under diagnosed and undertreated. The adverse ischemic heart disease is leading cause of death, less common in young women, where myocardial infarction (MI) mortality is two-fold higher in women younger than 50 years compared with age-matched men. The literature suggests that when women look like men, with male-pattern obstructive cardiovascular diseases (CHD), they are more likely to be diagnosed

Correspondence: Tiziana Ciarambino, Department of Internal Medicine, Santa Maria della Pietà Hospital Nola (NA), Italy. Tel.: +39.081.5666037.

E-mail: tiziana.ciarambino@gmail.com

Key words: Cardiovascular disease; gender-related differences; diabetes mellitus.

Conflict of interest: the authors declare no conflict of interest.

Received for publication: 21 March 2017.

Revision received: 8 January 2018.

Accepted for publication: 29 January 2018.

This work is licensed under a Creative Commons Attribution NonCommercial 4.0 License (CC BY-NC 4.0).

CCopyright T. Ciarambino et al., 2018

Licensee PAGEPress, Italy

Italian Journal of Medicine 2018; 12:23-31

doi:10.4081/itjm.2018.864 and treated like men. Two new analyses suggest that the Yentl syndrome is alive and well 10 years later. The first event in women takes about 10-20 years later than men. Women are more likely than men to have highrisk presentations and less likely to manifest central chest pain. ${ }^{1,3}$ Pain in the upper back, arm, neck, and jaw, as well as unusual fatigue, dyspnea, indigestion, nausea/vomiting, palpitations, weakness, and a sense of dread, occur more frequently in women compared with men. The absence of chest pain or silent heart attack is more common in women than in men $(35 \%$ vs $28 \%$ ). So, women often turn later to the doctor and are treated less aggressively. ${ }^{1}$ Cardiovascular disease is the most common cause of death and hospitalization in worldwide. Recognition of important gender differences plays an important role in cardiovascular disease prevention. New sensitivity about gender differences, and particularly attention among women, will be necessary for more analytic view about cardiovascular disease in both sexes.

\section{Possible causes}

The Framingham study already described the risk factors for CHD in women; then the INTERHEART, conducted in 52 countries around the world, identified nine risk factors, measurable and modifiable. These factors measurable and modifiable are: i) smoking; ii) hypertension; iii) diabetes; iv) dyslipidemia; v) abdominal obesity (waist/hip ratio); vi) stress and psychosocial factors; vii) physical inactivity; viii) low intake of fruits and vegetables; ix) alcohol. More risk factors greatly multiply the probability of infarction. ${ }^{4,5}$ These risk factors explain more than $90 \%$ of myocardial infarctions and in about $96 \%$ of CHD in women. For example, in women, it has been shown that family and marital stress increase the risk of 
ischemic heart disease. In women there is another condition that simulates the coronary heart disease. This condition is the Takotsubo syndrome. ${ }^{6-16}$ Depression is one aspect of psychosocial stress and more women become ill with depression after myocardial infarction than men. In addition, noneditable factors are identified, as genetic causes and endothelial dysfunction, as reported:

- Genetic causes: the genes of pseudo-autosomal region of the $\mathrm{X}$ chromosome encode enzymes involved in oxidative stress, cell survival, apoptosis and fat distribution. As modulated by its silencer, the dual presence of the $\mathrm{X}$ chromosome in women is therefore a protective factor. ${ }^{6}$

- Endothelial dysfunction: the WISE study showed that the prevalence of micro vascular disease in women, is due by typically feminine condition with endothelial dysfunction, impaired arterial compliance, micro vascular dysfunction in vessels that are smaller and deeper. In women prevails coronary dissection, a rare, but increasing and typical of young women of childbearing age $(80 \%$ of cases), with very high mortality and related to hormonal influence. ${ }^{10}$ Endothelial progenitor cells maintain the integrity and vascular homeostasis; their function (migratory capacity and to form colonies) appears to be controlled by estrogen and appears to be an independent marker of vascular integrity. A lower migratory capacity in women appears to be related to increased endothelial dysfunction. ${ }^{11}$

\section{Age: gender-related differences}

In elderly women, the destabilization of atherosclerotic plaque and plaque rupture occur with a very similar process to that of men. On the contrary, in old women, acute coronary syndrome and sudden death recognize as pathophysiological mechanism mainly the erosion of plaque in the presence of a strong local inflammation, with a mortality rate approximately double in women than in men. ${ }^{7,8}$ In the study GUSTO IIb, the incidence of ST-segment elevation myocardial infarction is lower in women, but, in some studies, an increased mortality after adjustment for comorbidities and age has been reported, due to more frequent post-infarct mechanical complications (mitral regurgitation acute heart failure, ventricular septal defect, ruptured papillary muscle and heart breaking). ${ }^{9}$

\section{Physiological aspects and pharmacokinetic parameters: gender-related differences}

Many physiological aspects, especially hormone metabolism influence therapeutic responses. Gender differeces are due to pharmacokinetic parameters, biovailbility, distribution, metabolism excretion and differences in weight and body surface area, extent and distribution of adipose tissue, plasma volume, rate of gastric emptying, concentration of plasma proteins, cytochrome system activity liver wings, function of membrane transporters [the verb in this sentence is missing; please rephrase]. A significant mortality reduction in women has emerged in the meta-analysis that included major studies on the use of $\beta$-blockers in secondary prevention. While the use of angiotensinconverting-enzyme inhibitor (ACE-I) showed similar reductions in mortality by gender. Analysis sub-group in patients treated with angiotensin receptor blockers (ARBs) indicates favorable effects on mortality regardless of gender. ${ }^{17}$ In women, acetylsalicylic acid for secondary prevention showed a statistically significant reduction in the risk of stroke, while it is not showed a consistent reduction of myocardial infarction or mortality. ${ }^{18}$

\section{Percutaneous and surgical revascularization: gender-related differences}

As for the percutaneous and surgical revascularization, women candidate for percutaneous angioplasty (PCI)/by pass aortic are on average older than men with higher prevalence of comorbidities (diabetes, hypertension, heart failure). Some authors have correlated the smaller size of the coronary arteries with worse outcomes, suggesting that the lower success rate of revascularization and the highest rate of complications are correlated with technical difficulties of surgical intervention. Other studies have not confirmed these data after adjustment for body surface area and risk factors, although the incidence of re-stenosis after PCI seems to be higher in women. Numerous studies have shown the delayed percutaneous revascularization in women, even if the effect of gender on mortality is minimal. ${ }^{19}$ Considering the different clinical presentation and inadequate control of risk factors in women, the diagnosis is often delayed. In fact, there are gender differences in the use of procedures, unless women do not meet the standards of a male model, and that definitely determines the worst cardiovascular prognosis in women than in men. Yet, as shown by the COURAGE study, women receive less drug prescriptions to treat coronary ischemia despite a similar benefit and similar frequency of adverse drug events in the two genders. ${ }^{20}$

\section{Atrial fibrillation: gender-related differences}

Atrial fibrillation (AF) is the most common cardiac arrhythmia, affecting more than 3 million people in the United States. ${ }^{21}$ The lifetime risk for developing $\mathrm{AF}$ for men and women aged more than 40 years is 
$1: 4$, respectively. ${ }^{22} \mathrm{~A}$ rising number of papers analyze sex-gender differences in treatment and mortality among patients with $\mathrm{AF}^{23}$ Women with $\mathrm{AF}$ seem to have an increased risk for cardiovascular events, including stroke ${ }^{24}$ and underutilization of oral anticoagulant (OAC) treatment among women has been suggested to be a contributing factor. ${ }^{25}$ However, studies have reported significant gender differences in the anti-arrhythmic strategy. In particular, in ATA-AF study the preferred anti-arrhythmic strategy was heart rate control in $54.7 \%$ of female, compared to $48.4 \%$ of male subjects, while the rhythm control was preferred in $29.5 \%$ of male compared to $25.1 \%$ of female subjects. Compared with males, female patients less frequently underwent electrical cardio version, as well as ablation and implantation or revision of pacemaker/implantable cardioverter defibrillator. At discharge, amiodarone and ACE-I were preferred in male subjects, while ARBs and diuretics were more frequently prescribed in female subjects. ${ }^{26}$ Other studies have reported a significant negative association between the $\mathrm{CHADS}_{2}$ score and left atrial emptying fraction only in women. ${ }^{27}$ Many studies reported that despite a similar extent of remodeling, the pattern in women had greater atrial myocardial deformation and smaller RA size. ${ }^{28}$ The GARFIELD-AF study found that women had a higher risk of stroke than men even after adjustment of risk factors (congestive heart failure, age, hypertension, diabetes mellitus, prior stroke, vascular disease and history of bleeding). The results from the GARFIELD-AF study, found that the mortality was only slightly elevated in women (4.48) compared with men (4.04). ${ }^{29}$ To this regard, there was a greater proportion of women over 75 years at the time of diagnosis of non-valvular AF. ${ }^{30}$ However, there was also a trend toward a greater prevalence of comorbid vascular disease in men (than women) and comorbid hypertension in women. Otherwise, the prevalence of other risk factors for stroke (diabetes, prior stroke) is similar in men and women. The Framingham study found that gender differences in blood pressure gradually narrow with age. Eventually, women develop higher blood pressure than men (beyond 60 years of age) with the accelerated onset of arterial stiffening beyond menopause (especially in women with a history of hypertension). ${ }^{31}$ For example, women require less warfarin to maintain a therapeutic international normalized ratio than men at an equivalent age and dosing reduces proportionally with increasing age. The greater risk of bleeding in men may be explained by their more aggressive OAC therapy dosing relative to women. Conversely, the lower impact of OAC treatment on stroke rates in women may be due to poorer anticoagulation control as determined by atrial fibrillation follow-up investigation of rhythm management (AFFIRM). ${ }^{32}$ An important consideration concerning women is the impact of age on prescribing practice and adherence to medication, since a higher proportion of women than men were elderly (75 years or older). There is also evidence that women with AF have a significantly greater residual risk of stroke (compared with men) when treated using warfarin.

\section{Arterial hypertension: gender-related differences}

\section{Introduction}

One of the largest studies that gives us information regarding the prevalence of hypertension and in particular according to gender, is the NHANES III study, ${ }^{33}$ which involves non-institutionalized population of the United States. The authors found that $24 \%$ of American subjects were hypertensive and that this percentage was slightly higher among males $(24.7 \%)$ compared to females (23.4\%). ${ }^{33}$ When they looked at the different distribution according to the age range, they observed that the prevalence of hypertension was higher among man compared to female up to 59 years of age, then there is a reverse trend from 60 years of age among Mexicans and non-Hispanic blacks, and from 70 years of age among non-Hispanic whites. ${ }^{33}$ From 80 years of age the prevalence of hypertension becomes $14.2 \%$ higher in women compared to men. ${ }^{33}$ Moreover, the authors observed a different trend of systolic and diastolic blood pressure (BP) according to gender. Systolic BP is higher in young men compared to young females. In fact, in young men the most frequent form of hypertension is isolated systolic hypertension; then among females there is a steeper rise of systolic BP up to the seventh decade, after that, systolic BP is similar in the two genders or slightly higher in males. ${ }^{33}$ Diastolic BP is higher in men compared to females during adulthood, while in older ages diastolic BP levels are similar in the two genders. ${ }^{33}$

\section{Age: gender-related differences}

In a recent study it was demonstrated that women after gestational hypertension presented an increased risk of future hypertension and of an earlier hypertension development compared to women that did not experienced gestational hypertension during pregnancy. ${ }^{34}$

BP rises after menopause in most women and it has been postulated that withdrawal of endogenous estrogen, a potent vasodilator, plays a key role in postmenopausal hypertension. ${ }^{35}$ Several mechanisms may be supposed to be responsible for this BP rise: increase of salt sensitivity, decrease of nitric oxide production, overexpression of type 1 angiotensin II receptor. ${ }^{36}$ Estrogens are supposed to protect from high BP levels by strengthening the correlation between pressure and salt excretion and promoting nitric-oxide synthetize 
activity and nitric oxide production. In particular, a previous study that involves more that $>22,000$ Italian female patients showed that menopause has a double risk of developing sustained hypertension. ${ }^{37}$ Another problem that arises with menopause is hormone replacement therapy (HRT) and in literature is still debated the possible unfavorable role of HRT. In a recent paper $^{38}$ that involves 43,405 non-hypertensive women before menopause, it was demonstrated that HRT was associated with a significant increased risk of elevated BP levels correlated to the duration of the therapy. In contrast, in another study that evaluated transdermal estrogen replacement therapy, a BP reduction was found..$^{39}$ In 2014, Cannoletta et al. concluded that HRT was associated with negative effects when it was started some years after the beginning of menopause. The authors reported that if HRT was started earlier and, in particular, with transdermal estradiol or with an association including progesterone (especially drospirenone), seemed to have a favorable effect on BP reduction. ${ }^{40}$

\section{Pharmacological treatment: gender-related differences}

Regarding pharmacological effect according to gender we have to take into account the unequal representation of both genders in population studies (usually $44 \%$ of female) and the lack of specific results according to genders. ${ }^{41,42}$ In the European Society of Hypertension guidelines the authors reported the results of a sub-analysis of 31 randomized controlled studies that demonstrated a similar BP reduction in both genders with similar effect with any drugs (calcium antagonists, ARB, ACE-I, $\beta$-blockers, diuretics) ${ }^{43}$ However, in literature some differences were described for diuretics with better response among women. During menopause, women presented a greater salt-sensitivity, so diuretics may be useful to promote renal sodium excretion and BP reduction, ${ }^{36}$ moreover a beneficial effect on calcium metabolism, with a consequent inferior risk of hip fracture, was described. ${ }^{44}$ Diuretics present also different side effects according to gender: among women sodium and potassium reduction, while an increased risk of gout among men. ${ }^{44}$ Moreover among women cough with ACE-I and peripheral edema with calcium antagonist are more common. ${ }^{44,45}$ Finally, sexual dysfunction, a typical male gender side effect, is described also in women correlated to $\beta$-blockers, thiazide diuretics and centrally active agents, while this effect is less pronounced with ARBs. ${ }^{45}$ Data from US populations ${ }^{46,47}$ showed that BP control in adult to elderly females (65-80 years of age) is lower compared to males. It is still debated if this phenomenon is due to a less intensive treatment, because of medical inertia, to a less adherence in this gender, or to the higher prevalence of resistance hypertension, in this age range, among females.

\section{Venous thromboembolism: gender-related differences}

Venous thrombosis, including deep vein thrombosis and pulmonary embolism (PE) occurs at an annual incidence of about 1 per 1000 adults. ${ }^{48}$ Venous thromboembolism (VTE) is predominantly a disease of older age, and is rare prior to late adolescence. ${ }^{49}$ Incidence rates increase markedly with age for men and women. The overall age-adjusted annual incidence rate is higher for men $(130$ per 100,000$)$ than for women $(110$ per $100,000) .{ }^{50}$ Incidence rates are somewhat higher in women during childbearing years (16-44 years) compared with men of similar age, whereas incidence rates in individuals aged $>45$ years are generally higher in men (Figure 1). PE accounts for an increasing proportion of VTE with increasing age in both sexes. ${ }^{49}$

VTE is a complex (multifactorial) disease, involving interactions between acquired or inherited predispositions to thrombosis and VTE risk factors, including increasing patient age and obesity, hospitalization for surgery or acute illness, nursing-home confinement, active cancer, trauma or fracture, immobility or leg paresis, superficial vein thrombosis, and, in women, pregnancy and puerperium, oral contraception, and hormone therapy. ${ }^{51}$

\section{Venous thromboembolism in pregnancy and the puerperium}

In the western world, venous thromboembolism in pregnancy and the puerperal period has been either the most common cause of maternal death ${ }^{52}$ or ranked closely behind sepsis and preeclampsia/eclampsia. Although the absolute incidence of venous thromboembolism in pregnancy is slow ( 1 or 2 cases per 1000 pregnancies), ${ }^{53}$ this risk is approximately 5 -fold higher in pregnant women than in non-pregnant women of the same age due to the changes in the coagulation and venous system associated with pregnancy. Venous stasis is probably caused by progesterone induced vasodilation and pelvic venous compression by uterus. Furthermore, the hemostatic system is progressively activated to prepare the delivery: the activity of protein $\mathrm{S}$ is reduced and the activated protein $\mathrm{C}$ resistance is progressively high. Thrombotic events are spread across the 3 trimesters. ${ }^{54}$

The risk increases further in the puerperium (the 6-week period after delivery), probably owing to endothelial damage to the pelvic vessels. Recent data indicate that an increased relative risk persists until 12 weeks after delivery. ${ }^{55}$ Multiple risk factors often coexist in women who developed VTE in pregnancy and 
one of the strongest risk factors is previous pregnancyrelated VTE event. ${ }^{56}$ Treatment of VTE in pregnancy involves unfractionated heparin or low-molecular weight heparin (LMWH), which do not cross the placenta or enter breast milk. In contrast to vitamin $\mathrm{K}$ antagonists that do cross placenta and can cause embryopathy. However, since warfarin crosses minimally into breast milk, it can be used in breast-feeding women during the post-partum period. LMWH is generally safe and easy to use with either once daily or twice daily dosing. ${ }^{56}$ The new anticoagulant (dabigatran, rivaroxaban, apixaban and edoxaban) may cross the placenta and should be avoided in pregnancy. ${ }^{56}$

\section{Venous thromboembolism and combined hormonal contraceptive: lights and shadows}

Contraceptive pills are among the most popular contraception methods worldwide. Despite their reliable contraception action, these pills may present side effects including VTE. Use of combined hormonal contraceptives (CHC) increased a two- to four-fold the risk of VTE compared with non-user, although the absolute risk of VTE with use of any types of combined oral contraceptives in young women is less than one in 1000 user a year. ${ }^{57}$ Sex hormones alter procoagulant protein levels, platelet function, and the vessel wall in a manner that may translate into gender-based differences in thrombosis. ${ }^{58}$ All currently used oral contraceptives are equally effective in preventing pregnancy but different combination pills show different VTE risk. Evaluation of these different tendencies may play an important role in choosing the safest pill when starting pill use. ${ }^{59}$ The estrogen dose was positively associated with the risk of VTE for preparations containing desogestrel and gestodene most commonly used. The oral contraceptives currently prescribed which contain $30 \mu \mathrm{g}$ of ethinylestradiol are associated with a higher risk of venous thrombosis than contraceptives containing $20 \mu \mathrm{g} .{ }^{60,61}$ Furthermore the risk of VTE is associated with different types of progestogens in combined oral preparations. It was shown that thirdgeneration CHCs users had a higher risk of VTE than second-generation users. ${ }^{62,63}$ The use of drospirenone in a CHC has been shown to increase the risk of VTE, compared with second-generation contraceptives. The risk among women using combined oral contraceptives decreased with duration of use. ${ }^{64}$ Women who use transdermal patches or vaginal rings for contraception have a 7.9 and 6.5 times increased risk of confirmed VTE compared with non-users of the same age, corresponding to 9.7 and 7.8 events per 10,000 exposure years. Progestogen-only pills and hormone releasing intrauterine devices did not confer any increased risk of VTE. ${ }^{65} \mathrm{CHCs}$ have been associated with an increased risk of arterial thrombosis but the magnitude of the risk and the effect of different hormonal contents remain unclear. ${ }^{66,67}$ The European Medicines Agency (EMA) and the Italian Pharmaceutical Agency (Agenzia Italiana del Farmaco - AIFA) have concluded that the benefits of CHCs in preventing unwanted pregnancies continue to outweigh their risks, and that the wellknown risk of VTE with all CHCs is small. It is important that women are made aware of the risk of VTE and its signs and symptoms, and that doctors take into consideration a woman's individual risk factors when prescribing a contraceptive. ${ }^{68}$ Universal screening for thrombophilia before the administration of oral contraceptives is not warranted. However, selective screening of women with a family history of thrombosis and thrombophilia before administration of hormonal therapy might be cost-effective.

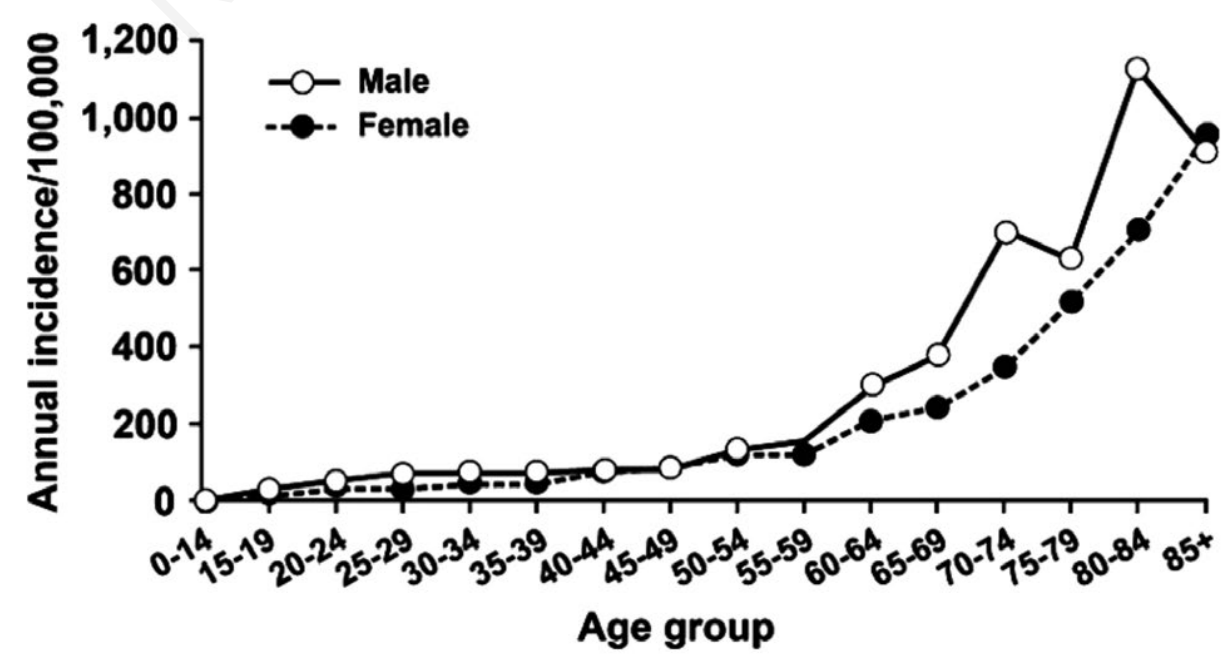

Figure 1. Annual incidence of venous thromboembolism by age and sex. 


\section{Diabetes and cardiovascular risk: gender-related differences}

\section{Introduction}

The prevalence of diabetes mellitus (DM) is increasing at a rapid rate. Currently, $\approx 1$ in 13 people living in the United States has DM, and $90 \%$ to $95 \%$ of these individuals have type 2 DM (T2DM). Overall, the prevalence of T2DM is similar in women and men ${ }^{69}$ Cardiovascular disease (CVD) is a major cause of morbidity and mortality for both men and women with diabetes, with huge socioeconomic costs. In the US, mortality rates have declined among men with diabetes, but not among women. ${ }^{70}$ Estimates of CVD mortality in men with diabetes have varied from 1 to 3 times the rate in men free of the disease, whereas estimates in women with diabetes have ranged from 2 to 5 times the rate in women without diabetes. ${ }^{71,72} \mathrm{~A}$ potential reason for differences in outcomes between men and women with T2DM is differential cardiovascular risk factor control and management.

\section{Coronary heart disease and diabetes: gender-related differences}

Type 2 diabetes has long been known as a risk factor for coronary heart disease and is estimated to increase the risk of a fatal event by twofold. ${ }^{69}$ The association between diabetes and coronary heart disease has been suggested to be stronger in women than in men, prompting the idea that diabetes eliminates, or substantially attenuates, the advantages of being female. ${ }^{73}$

The relative risk for fatal coronary heart disease associated with diabetes is $50 \%$ higher in women than it is in men, even after differences in other major cardiovascular risk factors have been taken into account. ${ }^{72}$ This greater excess coronary risk may be explained by more adverse cardiovascular risk profiles among women with diabetes, combined with possible disparities in treatment that favor men. Despite the fact that in many industrialized countries women have lower mortality rates than men, when we look at people with diabetes, the advantage for women is reduced or even absent. ${ }^{74}$ Compared to males, females with diabetes have a worse cardiovascular profile, which could explain their higher cardiovascular mortality, mainly at age $<60$. Diabetic females have higher prevalent abdominal obesity, increasing the risk of hypertension, a worse lipid profile (low levels of highdensity lipoproteins cholesterol, small particle size of low-density lipoproteins cholesterol, and high levels of triglycerides), and a more marked endothelial dysfunction, a greater degree of fibrinolysis/thrombosis, and also an increased prevalence of hypoglycemic events compared to that of male diabetic patients. ${ }^{75}$ These phenomena might explain the increased inci- dence of cardiovascular events and mortality among female patients. ${ }^{76}$ Besides innate differences in sex physiology, disparities between sexes in the treatment of major cardiovascular risk factors also exist. ${ }^{77}$ These can be attributed to an underestimation of patient risk and a less aggressive approach and poorer compliance of females. ${ }^{71}$ Nevertheless, two Italian studies did not find any relevant differences between females and males in terms of the quality of diabetes care, ${ }^{77-79}$ suggesting that factors other than gender disparities in treatment intensity are responsible.

Myocardial infarction occurs earlier and has higher mortality in women with DM compared with men, and revascularization rates (angioplasty, coronary artery bypass grafting) are lower in women with DM compared with men. T2DM is an especially powerful risk factor in young women, increasing their risk of CHD, including ACS, by 4 - to 5 -fold. ${ }^{80}$

Evolving sex-specific research has demonstrated that although men and women share similar risk factors for CHD, certain risk factors are more potent in women. These include tobacco abuse, T2DM, depression, and other psychosocial risk factors. The INTERHEART study identified DM as a potentially modifiable risk factors for MI. ${ }^{81}$

\section{Heart failure and diabetes: gender-related differences}

Heart failure is strongly related to DM, probably at least in part by its strong association with ischemic heart disease. The risk of heart failure increases by $40 \%$ in the presence of DM. ${ }^{82}$ There is a sex difference in this risk, shown first in the Framingham Heart Study in which heart failure risk was 2-fold higher in men $(\mathrm{P}<0.05)$ and 5 -fold higher in women with DM $(\mathrm{P}<0.01)$ compared with the respective non-diabetic population. ${ }^{83}$ In a more recent report, despite no difference in hospitalization among women with DM compared with men, the association between the diagnosis of heart failure and that of DM had a characteristic horseshoe shape over a 70-year age span with a relatively early rise followed by a progressive decrease with advancing age. ${ }^{84}$ This association was greater among women in the fourth and fifth decades of age compared with men. The underlying reason for the increased risk of developing heart failure in women with DM compared with men with DM is not entirely clear but most likely relates to the sex disparities at play in CHD diagnosis and treatment.

\section{Stroke and diabetes: gender-related differences}

$\mathrm{DM}$ is widely recognized as a risk factor for stroke in both women and men. ${ }^{85}$ Whether this sex difference also exists for stroke remains uncertain. Findings from previous studies have been inconsistent, with some in- 
vestigators reporting either a stronger, similar, or weaker effect of diabetes on stroke risk in women compared with men with DM. In a recent comprehensive systematic review and meta-analysis using data from 64 cohorts including $>12,000$ strokes, DM was a stronger risk factor for stroke in women than in men. Compared with men with DM, women with DM had a $27 \%$ greater relative risk (RR) for stroke when baseline differences in other cardiovascular risk factors were taken into account $[\mathrm{RR}=1.27 ; 95 \%$ confidence interval (CI), 1.10-1.46] ${ }^{86}$ These data add to the existing evidence that men and women experience diabetes-related diseases differently and suggest the need for further work to clarify the biological, behavioral, or social mechanisms involved.

The most recent American Heart Association (AHA) guidelines on the prevention of stroke in women classified DM as a risk factor that is stronger or more prevalent in women. ${ }^{87}$ In the Nurse's Health Study, among middle-aged women, those with T2DM had an almost 2-fold higher risk ( $\mathrm{RR}=1.8 ; 95 \% \mathrm{CI}$, 1.7-2.0) of total stroke than non-diabetic women. Among 30,000 women and men with T2DM, women with $\mathrm{HbA} 1 \mathrm{c}$ levels $\geq 8.0 \%$ had a significantly elevated risk of stroke, whereas men did not. ${ }^{88}$

\section{Conclusions}

It is imperative that women with DM are accurately informed about CVD risk factors, educated on how to reduce them, and aggressively treated to avoid adverse outcomes. Additional research involving women is needed to explore and reduce disparities in CVD risk between men and women with T2DM.

\section{References}

1. Jacobs AK, Eckel RH. Evaluating and managing cardiovascular disease in women: understanding a woman's heart. Circulation 2005;111:383-4.

2. Healy B. The Yentl Syndrome. N Engl J Med 1991;325: 274-5.

3. Leuzzi C, Sangiorgi GM, Modena MG. Gender-specific aspects in the clinical presentation of cardiovascular disease. Fundam Clin Pharmacol 2010;24:711-7.

4. Wilson PW, Meigs JB. Cardiometabolic risk: a Framingham perspective. Int J Obes (Lond) 2008;32:S17-20.

5. Yusuf S, Hawken S, Ounpuu S, et al. for the INTERHEART Study Investigators. Effect of potentially modifiable risk factors associated with myocardial infarction in 52 countries (the INTERHEART study): case-control study. Lancet 2004;364:937-52.

6. Arain FA. Sex/gender medicine the biological basis for personalized care. Cardiovascular Med Circ J 2009; 73:1774-82.

7. Farb A, Burke A, Tang A, et al. Coronary plaque erosion without rupture into a lipid core: A frequent cause of coronary thrombosis in sudden coronary death. Circulation 1996;93:1354-63.

8. Fuster V, Alexander RW, O'Rourke RA, et al. Women and cardiovascular disease. In: Hurst's the heart. Vol. 12. 11 th ed. New York, NY: McGraw Hill Companies, Inc.; 2004. pp 2291.

9. Brener SJ. Angioplasty or fibrinolysis for acute MI? The GUSTO IIB Study. Cleve Clin J Med 1998;65:75-81.

10. Gulati M, Shaw LJ, Bairey Merz CN. Myocardial ischemia in women: lessons from the NHLBI WISE study. Clin Cardiol 2012;35:141-8.

11. Campesi I. Relazione finale - Gender Innovation - Influenza del determinante genere su EPC Umane; 2014. Available from: http://archiviosif.org/infos/sif_relaz campesi_2014.pdf

12. Kurisu S, Sato H, Kawagoe T, et al. Takotsubo like left ventricular dysfunction with ST segment elevation: a novel cardiac syndrome mimicking acute myocardial infarction. Am Heart J 2002;143:448-55.

13. Rosengren A, Hawken S, Ounpuu S, et al. Association of psychosocial risk factors with risk of acute myocardial infarction in 11119 cases and 13648 controls from 52 countries (the INTERHEART study): case-control study. Lancet 2004;364:953-62.

14. Naqvi TZ, Naqvi SSA, Bairey Merz. Gender differences in the link between depression and cardiovascular disease. Psychosomatic 2005;67:15-28.

15. Lindwall-Sundel K, Andersson A. High frequency of anxiety and angina pectoris in depressed women with coronary heart disease. J Gender Med 2007;4:146-56.

16. Somberg TC, Arora RR. Depression and heart disease: therapeutic implications. Cardiology 2008;111:75-81.

17. Anthony M, Berg MJ. Biologic and molecular mechanisms for sex differences in pharmacokinetics, pharmacodynamics, and pharmacogenetics: Part II. Women Health Gend Based Med 2002;11:617-29.

18. Cook NR. A randomized trial of low-dose aspirin in the primary prevention of cardiovascular disease in women. N Eng J Med 2005;352:1293-304.

19. Kim C. A systematic review of gender differences in mortality after coronary artery bypass graft surgery and percutaneous coronary interventions. Clin Cardiol 2007;30:491-95.

20. Boden WE. Impact of optimal medical therapy with or without percutaneous coronary intervention on longterm cardiovascular end points in patients with stable coronary artery disease (from the COURAGE Trial). Am J Cardiol 2009;104:1-4.

21. Naccarelli GV, Varker H, Lin J, Schulman KL. Increasing prevalence of atrial fibrillation and flutter in the United States. Am J Cardiol 2009;104:1534-9.

22. Lloyd-Jones DM, Wang TJ, Leip EP, et al. Lifetime risk for development of atrial fibrillation: the Framingham Heart Study. Circulation 2004;110:1042-6.

23. Carlsson AC, Wändell P, Sundquist K, et al. Differences and time trends in drug treatment of atrial fibrillation in men and women and doctors' adherence to warfarin therapy recommendations: a Swedish study of prescribed drugs in primary care in 2002 and 2007. Eur J Clin Pharmacol 2013;69:245-53.

24. Cove CL, Albert CM, Andreotti F, et al. Female sex as an independent risk factor for stroke in atrial fibrillation: possible mechanisms. Thromb Haemost 2014;111:385-91. 
25. Gage BF, Boechler M, Doggette AL, et al. Adverse outcomes and predictors of underuse of antithrombotic therapy in medicare beneficiaries with chronic atrial fibrillation. Stroke 2000;31:822-7.

26. Politi C, Ciarambino T, Riva L, et al. Sex-gender and atrial fibrillation treatment in the AntiThrombotic Agents in Atrial Fibrillation (ATA-AF) study. Ital J Med 2016;10:64.

27. Yoshida K, Obokata M, Kurosawa K, et al. Effect of sex differences on the association between stroke risk and left atrial anatomy or mechanics in patients with atrial fibrillation. Circ Cardiovasc Imaging 2016;9:10.

28. Sanchis L, Sanz-De La Garza M, Bijnens B, et al. Gender influence on the adaptation of atrial performance to training. Eur J Sport Sci 2017;13:1-7.

29. Camm AJ, Accetta G, Al Mahmeed W, et al. Impact of gender on event rates at 1 year in patients with newly diagnosed non-valvular atrial fibrillation: contemporary perspective from the GARFIELD-AF registry. BMJ Open 2017;7:e014579.

30. Olesen JB, Fauchier L, Lane DA, et al. Risk factors for stroke and thromboembolism in relation to age among patients with atrial fibrillation: the Loire Valley atrial fibrillation project. Chest 2012;141:147-53.

31. Franklin SS, Gustin W IV, Wong ND, et al. Hemodynamic patterns of age-related changes in blood pressure. The Framingham Heart Study. Circulation 1997;96:308-15.

32. Sullivan RM, Zhang J, Zamba G, et al. Relation of gender-specific risk of ischemic stroke in patients with atrial fibrillation to differences in warfarin anticoagulation control (from AFFIRM). Am J Cardiol 2012;110:1799-802.

33. Burt VL, Whelton P, Roccella EJ, et al. Prevalence of hypertension in the US adult population. Results from the Third National Health and Nutrition Examination Survey, 1988-1991. Hypertension 1995;25:305-13.

34. Heida KY, Franx A, van Rijn BB, et al. Earlier age of onset of chronic hypertension and type 2 diabetes mellitus after a hypertensive disorder of pregnancy or gestational diabetes mellitus. Hypertension 2015;66:1116-22.

35. Hage FG, Mansur SJ, Xing D, Oparil S. Hypertension in women. Kidney Int Suppl 2013;3:352-6.

36. Kim JM, Kim TH, Lee HH, et al. Postmenopausal hypertension and sodium sensitivity. J Menopausal Med 2014;20:1-6.

37. Amigoni S, Morelli P, Parazzini F, Chatenoud L. Determinants of elevated blood pressure in women around menopause: results from a elevated blood pressure in women around menopause: results from a cross-sectional study in Italy. Maturitas 2000;34:25-32.

38. Chiu CL, Lujic S, Thornton C, et al. Menopausal hormone therapy is associated with having high blood pressure in postmenopausal women: observational cohort study. PLoS One 2012;7:7.

39. Akkad AA, Halligan AW, Abrams K, al-Azzawi F. Differing responses in blood pressure over 24 hours in normotensive women receiving oral or transdermal estrogen replacement therapy. Obstet Gynecol 1997;89:97-103.

40. Cannoletta M, Cagnacci A. Modification of blood pressure in postmenopausal women: role of hormone replacement therapy. Int J Womens Health 2014;6:745-57.

41. Blauwet LA, Hayes SN, McManus D, et al. Low rate of sex-specific result reporting in cardiovascular trials. Mayo Clin Proc 2007;82:166-70.
42. Gueyffier F, Boutitie F, Boissel JP, et al. Effect of antihypertensive drug treatment on cardiovascular outcomes in women and men. A meta-analysis of individual patient data from randomized, controlled trials. The INDANA Investigators. Ann Intern Med 1997;126:761-7.

43. Turnbull F, Woodward M, Neal B, et al. Do men and women respond differently to blood pressure-lowering treatment? Results of prospectively designed overviews of randomized trials. Eur Heart J 2008;29:2669-80.

44. Oprail S, Miller AP. Gender and blood pressure. J Clin Hypertens 2005;7:300-9.

45. Os I, Franco V, Kjeldsen SE, et al. Effects of losartan in women with hypertension and left ventricular hypertrophy results from the losartan intervention for endpoint reduction in hypertension study. Hypertension 2008;51:1103-8.

46. Ostchega Y, Dillon CF, Hughes JP, et al. Trends in hypertension prevalence, awareness, treatment, and control in older U.S. adults: data from the National Health and Nutrition Examination Survey 1988 to 2004. J Am Geriatr Soc 2007;55:1056-65.

47. Keyhani S, Scobie JV, Hebert PL, et al. Gender disparities in blood pressure control and cardiovascular care in a national sample of ambulatory care visits. Hypertension 2008;51:1149-55.

48. White RH. The epidemiology of venous thromboembolism. Circulation 2003;107:I-4-8.

49. Naess IA. Incidence and mortality of venous thrombosis: a population-based study. J Thromb Haemost 2007;5:692-9.

50. Silverstein MD. Trends in the incidence of deep vein thrombosis and pulmonary embolism: a 25-year population-based study. Arch Intern Med 1998;158:585-93.

51. Heit JA, Spencer FA, White RH. The epidemiology of venous thromboembolism. J Thromb Trombolysis 2016;41:3-14.

52. Morris JM, Algert CS, Roberts C. Incidence and risk factors for pulmonary embolism in the postpartum period. J Thromb Haemost 2010;8:998-1003.

53. Kane EV, Calderwood C, Dobbie R, et al. A populationbased study of venous thrombosis in pregnancy in Scotland 1980-2005. Eur J Obstet Gynecol Reprod Biol 2013;169:223-9.

54. James AH, Tapson VF, Goldhaber SZ. Thrombosis during pregnancy and the postpartum period. Am J Obstet Gynecol 2005;193:216-9.

55. Kamel H, Navi BB, Sriram N, et al. Risk of a thrombotic event after the 6-week postpartum period. N Engl J Med 2014;370:1307-15.

56. Bates SM, Greer IA, Middeldorp S, et al. VTE, thrombophilia, antithrombotic therapy, and pregnancy: Antithrombotic Therapy and Prevention of Thrombosis, 9th ed: American College of Chest Physicians EvidenceBased Clinical Practice Guidelines. Chest 2012;141: e691S-736S.

57. De Bastos M, Stegeman BH, Rosendaal FR, et al. Combined oral contraceptives: venous thrombosis. Cochrane Database of Systematic Reviews 2014;3: CD010813.

58. Bailey AL, Scantlebury DC, Smyth SS. Thrombosis and antithrombotic therapy in women. Arterioscler Thromb Vasc Biol 2009;29:284-8.

59. Van Hylckama Vlieg A, Helmerhorst FM, Vandenbroucke JP, et al. The venous thrombotic risk of oral contraceptives, effects of estrogen dose and progestogen 
type: results of the MEGA case-control study. BMJ 2009;339:b2921.

60. Stegeman BH, de Bastos M, Rosendaal FR, et al. Different combined oral contraceptives and the risk of venous thrombosis: systematic review and network meta-analysis. BMJ 2013;347.

61. Lidegaard O, Lokkegaard E, Svendsen AL, Agger C. Hormonal contraception and risk of venous thromboembolism: national follow-up study. BMJ 2009;339.

62. Vinogradova Y, Coupland C, Hippisley-Cox J. Use of combined oral contraceptives and risk of venous thromboembolism: nested case-control studies using the QResearch and CPRD databases. BMJ 2015;350:h2135.

63. Boef AGC, Souverein PC, Vandenbroucke JP, et al. Instrumental variable analysis as a complementary analysis in studies of adverse effects: venous thromboembolism and second-generation versus third-generation oral contraceptives. Pharmacoepidemiol Drug Saf 2016;25: 317-24.

64. Martinelli I, Maino A, Abbattista M, et al. Duration of oral contraceptive use and the risk of venousthromboembolism. A case-control study. Thromb Res 2016; 141:153-7.

65. Lidegaard O, Nielsen LH, Wessel SC, Lokkegaard E. Venous thrombosis in users of non-oral hormonal contraception: follow-up study, Denmark 2001-10. BMJ 2012;344:2990.

66. Roach RE, Helmerhorst FM, Lijfering WM, et al. Combined oral contraceptives: the risk of myocardial infarction and ischemic stroke. Cochrane Database of Systematic Reviews 2015;8:CD011054.

67. Lidegaard O, Lokkegaard E, Jensen A, et al. Thrombotic stroke and myocardial infarction with hormonal contraception. N Engl J Med 2012;366;24.

68. European Medicines Agency (EMA). Benefits of combined hormonal contraceptives (CHCs) continue to outweigh risks - CHMP endorses PRAC recommendation; 22 November 2013. Available from: http://www.ema.europa.eu/ema/index.jsp?curl=pages/news_and_events/ne ws/2013/11/news_detail_001969.jsp\&mid=WC0b01ac0 $58004 \mathrm{~d} 5 \mathrm{c} 1$

69. Centers for Disease Control and Prevention (CDCP). National diabetes statistics report: estimates of diabetes and its burden in the United States. Atlanta, GA: Centers for Disease Control and Prevention; 2014.

70. Gregg EW, Gu Q, Cheng YJ, et al. Mortality trends in men and women with diabetes, 1971 to 2000 . Ann Intern Med 2007;147:149-55.

71. Barrett-Connor EL, Cohn BA, Wingard DL, Edelstein SL. Why is diabetes mellitus a stronger risk factor for fatal ischemic heart disease in women than inmen? The Rancho Bernardo Study. J Am Med Assoc 1991;265:627-31.

72. Huxley R, Barzi F, Woodward M. Adverse effects of diabetes on multiple cardiovascular disease risk factors in women: the strong heart study. Br Med J 2006;332:73-6.

73. Regensteiner JG, Golden S, Huebschmann AG, et al. Sex differences in the cardiovascular consequences of diabetes mellitus. A scientific statement from the American Heart Association. Circulation 2015;22:1-29.
74. Roche MM, Wang PP. Sex differences in all-cause and cardiovascular mortality, hospitalization for individuals with and without diabetes, and patients with diabetes diagnosed early and late. Diabetes Care 2013;36:2582-90.

75. Kanaya AM, Grady D, Barrett-Connor E. Explaining the sex difference in coronary heart disease mortality among patients with type 2 diabetes mellitus: a meta-analysis. Arch Intern Med 2002;162:1737-45.

76. Kalyani RR, Lazo M, Ouyang P, et al. Sex differences in diabetes and risk of incident coronary artery disease in healthy young and middle-aged adults. Diabetes Care 2014;37:830-8.

77. Rossi MC, Cristofaro MR, Gentile S, et al. Sex disparities in the quality of diabetes care: biological and cultural factors may play a different role for different outcomes: a cross-sectional observational study from the amd annals initiative. Diabetes Care 2013;36:3162-8.

78. Bugiardini R, Yan AT, Yan RT, et al. Factors influencing underutilization of evidence-based therapies in women. Eur Heart J 2011;32:1337-44.

79. Penno G, Solini A, Bonora E, et al. Gender differences in cardiovascular disease risk factors, treatments and complications in patients with type 2 diabetes: the RIACE Italian multicentre study. J Intern Med 2013; 274:176-91.

80. Mehta S, Beckie TM, DeVon HA, et al. Acute myocardial infarction in women. A scientific statement from the American Heart Association. Circulation 2016;133.

81. Anand S, Islam S, Rosengren A, et al. Risk factors for myocardial infarction in women and men: insights from the INTERHEART study. Eur Heart J 2008;29:932-40.

82. Nichols GA, Gullion CM, Koro CE, et al. The incidence of congestive heart failure in type 2 diabetes: an update. Diabetes Care 2004;27:879-84.

83. Kannel WB, Hjortland M, Castelli WP. Role of diabetes in congestive heart failure: the Framingham study. Am J Cardiol 1974;34:29-34.

84. Seghieri C, Francesconi P, Cipriani S, et al. Gender effect on the relation between diabetes and hospitalization for heart failure. Exp Clin Endocrinol Diabetes 2012; 120:51-5.

85. O'Donnell MJ, Xavier D, Liu L, et al. INTERSTROKE Investigators. Risk factors for ischaemic and intracerebral haemorrhagic stroke in 22 countries (the INTERSTROKE study): a case-control study. Lancet 2010;376: 112-3.

86. Peters SA, Huxley RR, Woodward M. Diabetes as a risk factor for stroke in women compared with men: a systematic review and meta-analysis of 64 cohorts, including 775385 individuals and 12539 strokes. Lancet 2014;383:1973-80.

87. Bushnell C, McCullough LD, Awad IA, et al. Guidelines for the prevention of stroke in women: a statement for healthcare professionals from the American Heart Association/American Stroke Association. Stroke 2014;45: 1545-88.

88. Zhao W, Katzmarzyk PT, Horswell R, et al. Sex differences in the risk of stroke and $\mathrm{HbA}(1 \mathrm{c})$ among diabetic patients. Diabetologia 2014;57:918-26. 